\title{
TCEB2 confers resistance to VEGF-targeted therapy in ovarian cancer
}

\author{
ZHUO DENG ${ }^{1}$, JIANCHENG ZHOU ${ }^{2}, \mathrm{XI} \mathrm{HAN}^{1}$ and $\mathrm{XU} \mathrm{LI}^{1}$ \\ ${ }^{1}$ Center for Translational Medicine and, The First Affiliated Hospital of Xi'an Jiaotong University College of Medicine, \\ Xi'an, Shaanxi 710061; ${ }^{2}$ Department of Urology, Shaanxi Provincial People's Hospital, Xi'an, Shaanxi 710068, P.R. China
}

Received July 11, 2015; Accepted August 26, 2015

DOI: $10.3892 /$ or.2015.4388

\begin{abstract}
Targeted therapy has revolutionized the therapeutic landscape in oncology in recent years and anti-VEGF agent has been approved for ovarian cancer (OC). Unfortunately, the efficacy of this treatment is limited due to the development of resistance, while the molecular mechanisms underlying OC resistance to anti-VEGF therapy are less clear. In this study, we observed a differential response of OC cells to anti-VEGF agent bevacizumab (BV) by using xenograft models. Gene expression analysis showed that TCEB2 gene was significantly upregulated in the OC tumors with acquired resistance compared with the sensitive tumors. Further mechanism dissections demonstrated that TCEB2 played a critical role in the development of acquired resistance to $\mathrm{BV}$ in $\mathrm{OC}$ cells via promoting HIF-1 $\alpha$ degradation and suppressing VEGF-A expression. In TCEB2 overexpressing cells, interleukin- 8 (IL-8) was elevated and functioned as a compensatory angiogenesis signaling which was sensitive to IL-8 monoclonal antibody (IL-8 Ab). The combination of BV and IL-8 Ab exhibited synergistic effect of growth inhibition on both OC and endothelial cells. Thus, this study provides an alternative strategy of simultaneously targeting VEGF-A and IL-8 for combating OC.
\end{abstract}

\section{Introduction}

Ovarian cancer (OC) is the most lethal gynecologic malignancy and the fifth most common cause of cancer-related death in women (1). Surgical and chemotherapeutic management are the standard of care for this disease (2). However, most patients relapse after primary treatment and succumb to disease progression. In addition, although changes to both chemotherapy schedules and routes of administration

Correspondence to: Professor $\mathrm{Xu} \mathrm{Li}$, Center for Translational Medicine, The First Affiliated Hospital of Xi'an Jiaotong University College of Medicine, 277 Yanta West Road, Xi'an, Shaanxi 710061, P.R. China

E-mail: lixu1956@yahoo.com

Key words: TCEB2, VEGF-targeted therapy, HIF-1 $\alpha$, IL-8, ovarian cancer have improved patient survival to a degree, it appears that a therapeutic ceiling with chemotherapy has been reached $(3,4)$. OC still lags behind a number of other solid malignancies in terms of the sluggish incremental extension in overall survival during the last 20 years. This has led to a number of clinical trials in OC investigating the efficacy of molecular targeted therapies which have undoubtedly revolutionized the therapeutic landscape in oncology in recent years $(5,6)$.

Angiogenesis plays crucial roles in the development and progression of OC (7). Anti-angiogenic therapies mainly include agents targeting the vascular endothelial growth factor (VEGF) and agents targeting the VEGF receptors in tumor-associated endothelial cells. Anti-VEGF therapy seems to be a relevant strategy in OC (8). Bevacizumab (BV), a VEGF monoclonal antibody, is the first anti-angiogenic therapy proven to slow metastatic disease progression in patients with cancer. Addition of BV (given as concurrent or maintenance) to conventional chemotherapy has been shown to improve progression-free survival (PFS) in relapsed, platinum-resistant OC (9). Unfortunately, the efficacy of BV is limited and the clinical benefit is short-lived. Some patients do not respond to $\mathrm{BV}$ and most patients with initial response will rapidly develop resistant disease $(5,10,11)$. Currently, the molecular mechanisms underlying $\mathrm{OC}$ resistance to $\mathrm{BV}$ are less clear. Comprehensive understanding of OC resistance to anti-VEGF therapy help to identify early indicators of resistance and exploit better anti-angiogenic therapies.

TCEB2 encodes the protein elongin $\mathrm{B}$, which is a subunit of the transcription factor B (SIII) complex and is also reported to function as an adapter protein in the proteasomal degradation of target proteins via different E3 ubiquitin ligase complexes $(12,13)$. In the present study, we identified that TCEB2 is involved in the development of acquired resistance to $\mathrm{BV}$ in OC cells via the mechanisms of suppression of VEGF-A expression by promoting HIF-1 $\alpha$ degradation and induction of interleukin-8 (IL-8) expression. These findings thus may provide an alternative therapeutic strategy of combining anti-VEGF and anti-IL-8 regents for drug resistant OC cells.

\section{Materials and methods}

Cell culture. Human ovarian cancer cells SKOV3 and HO8910 were maintained in RPMI-1640 (Gibco, San Diego, CA, USA) 
medium supplemented with $10 \%$ fetal bovine serum (FBS), human umbilical vein endothelial cells (HUVEC) was maintained in endothelial cell medium containing 5\% FBS and 1\% endothelial cell growth supplement (ScienceCell). All cells were cultured in a humidified incubator at $37^{\circ} \mathrm{C}$ with $5 \% \mathrm{CO}_{2}$.

Reagents. MG132 and cycloheximide (CHX) were purchased from Sigma-Aldrich (St. Louis, MO, USA). Human VEGF monoclonal antibody bevacizumab (BV) was from Roche (Indianapolis, IN, USA), and human IL-8 neutralizing antibody (IL-8 Ab) was from R\&D Systems (Minneapolis, MN, USA). Monoclonal anti-HIF1 $\alpha$ was purchased from BD Biosciences (San Jose, CA, USA). Monoclonal anti-V5-tag and anti- $\beta$-actin were purchased from Santa Cruz Biotechnology (Santa Cruz, CA, USA).

Reverse transcriptional $(R T)$ real-time PCR. RT real-time PCR was performed as described (14). Total RNA was extracted and $1 \mu \mathrm{g}$ RNA was reverse transcribed with a cDNA Synthesis kit (Invitrogen, Carlsbad, CA, USA). Real-time PCR analysis was set up with SYBR Green qPCR SuperMix kit (Invitrogen) and carried out in the iCycler thermal cycler (Bio-Rad, Hercules, CA, USA). The relative level of mRNA expression of each gene was determined by normalizing with $\beta$-actin. The primers used are: $\beta$-actin, 5'-TACCACAGGCAT TGTGATGG-3' (forward) and 5'-TTTGATGTCACGCACGA TTT-3' (reverse); human TCEB2, 5'-GAGGCCCATTTCCCC CAATA-3' (forward) and 5'-ACAGGACAGCACAGGAA CTG-3' (reverse); and human VEGF-A, 5'-TACCTCCACCA TGCCAAGTG-3' (forward) and 5'-ATGATTCTGCCCTCCT CCTTC-3' (reverse).

Western blot analysis. Cells were harvested and lysed using ice-cold lysis buffer [150 mM NaCl, $1 \%$ Triton X-100, $0.5 \%$ sodium deoxycholate, $0.1 \%$ SDS, $50 \mathrm{mM}$ Tris $(\mathrm{pH} 8.0$ ), protease inhibitor cocktail (Roche)] for $45 \mathrm{~min}$. Lysates were then centrifuged at $14,000 \mathrm{rpm}$ for $10 \mathrm{~min}$ at $4^{\circ} \mathrm{C}$ to collect the supernate. Equivalent amount of proteins were separated by $12 \%$ sodium dodecyl sulfate-polyacrylamide gel electrophoresis and transferred to nitrocellulose membranes. Membranes were block with $5 \%$ skim milk containing $0.1 \%$ Tween-20 for $1 \mathrm{~h}$ at room temperature. Appropriate primary antibodies were added into the membranes overnight at $4^{\circ} \mathrm{C}$. Membranes were then washed and incubated with horseradish peroxidase conjugated secondary antibodies for $1 \mathrm{~h}$ at room temperature. Signals were then detected by chemiluminescence (Pierce, Rockford, IL, USA).

Transfection. TCEB2-overexpressing plasmid (pLenti6V5/TCEB2) and empty vector were purchased from DNASU Plasmid Repository (Tempe, AZ, USA). For transfection, $2 \times 10^{5}$ SKOV3 cells were seeded in 6 -well plate with $60 \%$ confluence prior to the transfection, $2.5 \mu \mathrm{g}$ pLenti6-V5/TCEB2 or empty vector were transfected into cells by $\mathrm{Xfect}^{\mathrm{TM}}$ transfection reagent (Clontech, Palo Alto, CA, USA) according to the manufacturer's instructions. Further assay was performed $48 \mathrm{~h}$ after the transfection.

Co-culture and cell proliferation assay. For SKOV3 cell proliferation assay, cells were re-suspended in medium and cultured in 96-well plates at a concentration of 2,000 cells/well. After the indicated treatment, cell viability was assessed using a 3-(4,5-dimethylthiazol-2-yl)-2,5-diphenyltetrazolium bromide (MTT) assay (Roche). For co-culture system, SKOV3 cells were plated in Transwell permeable support $(0.4 \mu \mathrm{m}$ pore size; Fisher Scientific) and HUVEC cells were plated in 12-well plates on the first day. Next day, Transwell inserts were placed on 12-well plates and co-culture medium (M199; Life Technologies) containing either vehicle, BV $(1 \mathrm{mg} / \mathrm{ml})$ or IL-8 Ab $(0.5 \mu \mathrm{g} / \mathrm{ml})$. After the treatment, HUVEC cells were fixed with $4 \%$ paraformaldehyde for $10 \mathrm{~min}$, stained with $0.5 \%$ crystal violet and washed twice, $0.5 \mathrm{ml} 30 \%$ acetic acid was then added into the plates to dissolve the crystal violet, and $0.2 \mathrm{ml}$ aliquot of the solution was added into a 96-well plate to read the absorbance values (optical density, OD) at $560 \mathrm{~mm}$.

HRE-luciferase assay. Cells seeded in 24-well plates were transfected with $1 \mu \mathrm{g}$ hypoxia response element (HRE) reporter gene luciferase constructs (HRE-Luc) and $2 \mathrm{ng}$ Renilla luciferase construct as internal control. Forty-eight hours after transfection, HRE-Luc activity was measured using dual luciferase assay kit according the manufacturer's protocol (Promega, Madison, WI, USA).

Animal experiments. All experimental procedures were approved by the Institutional Animal Care and Use Committee. SKOV3 cells $\left(3 \times 10^{6}\right)$ were subcutaneously injected into 4-6 weeks old athymic nude mice. Tumor volume was measured weekly after the injection, when tumor volume reached $50 \mathrm{~mm}^{3}, 10 \mathrm{mg} / \mathrm{kg}$ of BV or vehicle (PBS) was injected intra-peritoneally twice weekly for a total of 6 weeks. At the end of treatment, animals were sacrificed and fresh tumor tissues were collected for further studies.

Bioinformatic and statistical analysis. RNA-sequence-based mRNA expression data for TCEB2 and VEGF-A of ovarian cancer samples from The Cancer Genome Atlas (TCGA) were retrieved through the CGDS server of the cBioportal hosted by the Memorial Sloan-Kettering Cancer Center. Pearson's correlation analysis was performed to analyze the association between TCEB2 and VEGF-A. All the in vitro and in vivo data are presented as the mean \pm SEM from at least three independent experiments and the differences between two groups were compared by the Student's t-test. All statistical analyses were performed using SPSS 16.0 software.

\section{Results}

Heterogeneity of $O C$ cells in response to $B V . \mathrm{BV}$ has been shown to improve patient survival in OC, however, the efficacy is limited and the clinical benefit is short-lived, since the initial response rate of $\mathrm{OV}$ to $\mathrm{BV}$ is $<40 \%$ and most patients with initial response will eventually develop resistant disease $(5,10,11)$. Here, we established OC xenograft models and treated tumors with BV to determine 'sensitivity' or 'resistance'. The phenotypic sensitivity of each individual tumor to treatment was defined by a long-term trend toward tumor stasis (tumor volume increase of $<25 \%$ ). In contrast, tumors that increased $>25 \%$ of initial volume and showed a long-term trend toward continued growth were considered as resistance. 


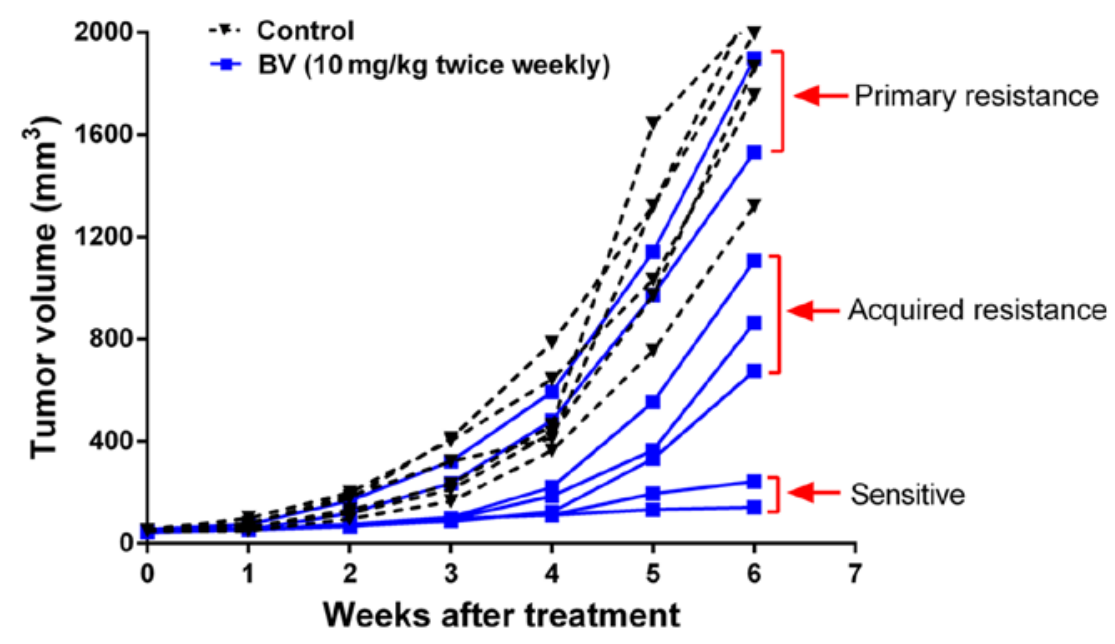

Figure 1. Differential response of ovarian cancers (OC) to VEGF-targeted therapy. SKOV3 cells were subcutaneously injected into nude mice and the tumors were treated with vehicle control or VEGF monoclonal antibody bevacizumab (BV, $10 \mathrm{mg} / \mathrm{kg}$ twice weekly) for 6 weeks. Tumor volume at the indicated time is shown and the differential response of each tumor to BV is marked.
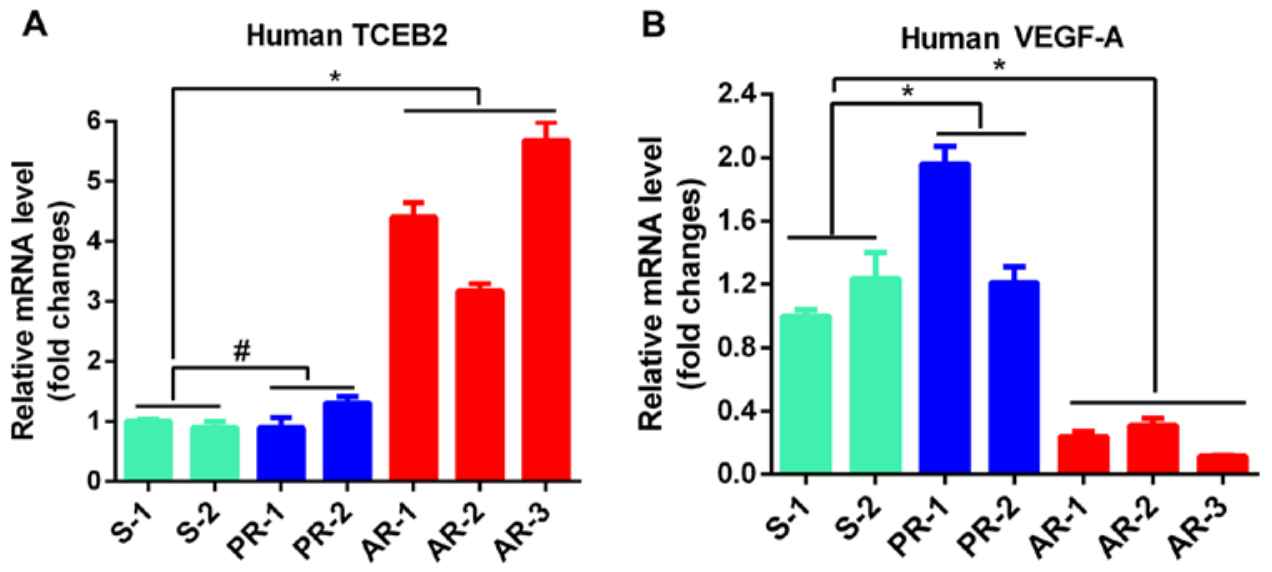

Figure 2. Expression of TCEB2 and VEGF-A in sensitive (S), primary resistant (PR) and acquired resistant (AR) OC subcutaneous tumors. Total RNA from the indicated tumors at the 6th week was exacted, and the mRNA expression of human TCEB2 (A) and VEGF-A (B) was analyzed by real-time PCR. " $\mathrm{P}<0.05$; ${ }^{\#} \mathrm{P}>0.05$.

The results showed that tumors treated with vehicle control (control) showed continued growth. Of the 7 tumors treated with BV, only 2 showed sensitivity, 2 were primary resistance to $\mathrm{BV}$ and 3 exhibited initial response to the treatment during the first 3 weeks of treatment but rapidly acquired resistant phenotype after that (Fig. 1). These results indicate that heterogeneity exists in the response of $\mathrm{OC}$ to $\mathrm{BV}$.

TCEB2 is associated with the development of resistance to $B V$ in $O C$ cells. We analyzed the differential expression of genes related to tumor angiogenesis in the sensitive (S), primary resistant (PR) and acquired resistant (AR) tumors to identify critical genes involved in the development of BV-resistance, and found that human TCEB2 gene was significantly increased in all the AR tumors $(\mathrm{P}<0.05)$, but no difference was observed in TCEB2 level between PR and $\mathrm{S}$ tumors ( $\mathrm{P}>0.05$, Fig. 2A), indicating that TCEB2 is associated with the development of AR in OC cells. In addition, the expression of human VEGF-A in tumors was determined, and the data indicated that VEGF-A was significantly decreased in all AR tumors compared to
$\mathrm{S}$ tumors (P<0.05, Fig. 2A), suggesting VEGF-A-independent manner of growth in AR tumors.

TCEB2 negatively regulates VEGF-A in the development of resistance to $B V$. To further confirm the role of TCEB2 in the development of BV-resistance, empty vector and TCEB2-overexpressing (pLenti6-V5/TCEB2) SKOV3 and HO8910 cells were established. Cells were then treated with $\mathrm{BV}$ and cell viability was examined. TCEB2-overexpressing cells were relatively resistant to BV compared to empty vector cells (Fig. 3A). Since tumor-associated vascular endothelium are known to be crucial for tumor growth and involved in resistance to anti-angiogenic therapies (15), co-culture models were used to mimic the interaction between tumor cells and vascular endothelium. Empty vector and TCEB2-overexpressing cancer cells co-cultured with HUVEC cells were then treated with BV, notably, HUVEC co-cultured with empty vector cells showed sensitive to BV but the HUVEC cells co-cultured with TCEB2-overexpressing cells were much more resistant to BV (Fig. 3B). These data 

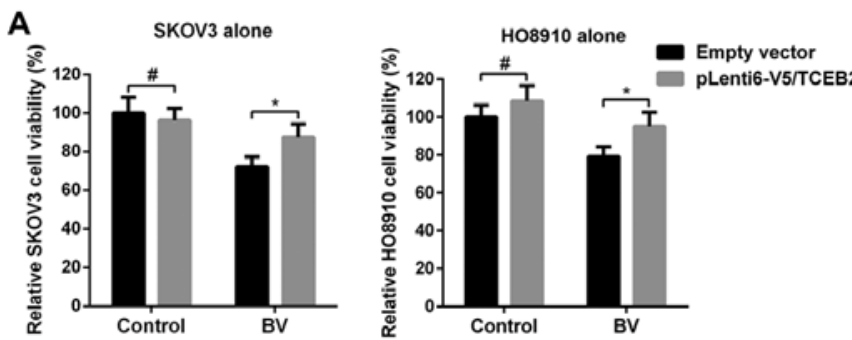

C
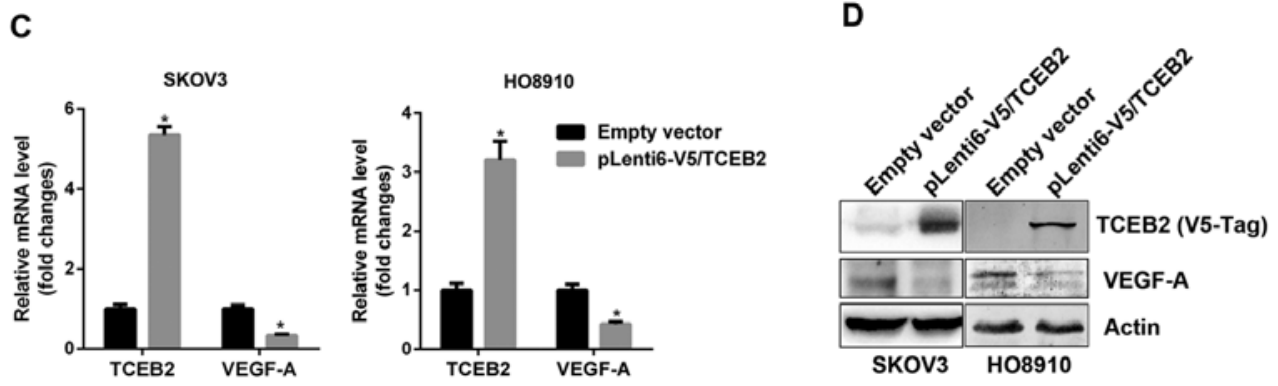
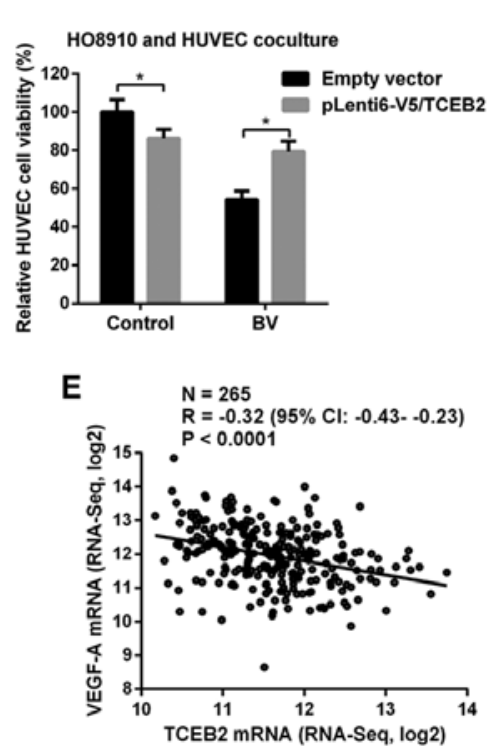

Figure 3. TCEB2 confers OC resistance to BV and negatively regulates VEGF-A expression. (A) Cell viability of empty vector or TCEB2-overexpressing SKOV3 and HO8910 cells treated with control or BV $(1 \mathrm{mg} / \mathrm{ml})$ for $48 \mathrm{~h}$. (B) HUVEC cells co-cultured with empty vector or TCEB2-overexpressing cancer cells were treated with control or BV for $48 \mathrm{~h}$, and the cell viability of HUVEC was analyzed by MTT assay. Real-time PCR (C) and western blot analysis (D) of TCEB2 and VEGF-A expression in empty vector or TCEB2-overexpressing SKOV3 and HO8910 cells. (E) Pearson's correlation analysis of TCEB2 and VEGF-A mRNA expression in human ovarian cancer tissues from TCGA (N, sample size number; R, Pearson's correlation coefficients). $\mathrm{P}<0.05$; ${ }^{\sharp} \mathrm{P}>0.05$.

clearly demonstrated that TCEB2 plays an essential role in the development of resistance to BV. Additionally, since increased TCEB2 and decreased VEGF-A were observed in AR tumors (Fig. 2), we hypothesized that TCEB2 negatively regulated VEGF-A. Indeed, TCEB2-overexpressing cells showed decreased VEGF-A mRNA and protein expression (Fig. 3C and D). Furthermore, by analysis of TCEB2 and VEGF-A expression in human OC tissues from The Cancer Genome Atlas (TCGA), we found an inverse correlation between these two genes in OC tissues (Fig. 3E). Taken together, these data suggest that in the development of AR, TCEB2 may promote OC cells to escape from BV treatment by VEGF-A suppression.

TCEB2 promotes HIF-1 $\alpha$ degradation. HIF-1 $\alpha$ is a well-known transcription factor directly controlling VEGF-A expression in most tumor cells (16). We examined the expression of HIF-1 $\alpha$ in empty vector and TCEB2-overexpressing SKOV3 cells, and found HIF-1 $\alpha$ mRNA level was unchanged (Fig. 4A). However, TCEB2-overexpressing cells exhibited decreased HIF-1 $\alpha$ protein, and the treatment of a proteasome inhibitor, MG132, abolished the difference in HIF-1 $\alpha$ level between empty vector and TCEB2-overexpressing cells (Fig. 4B). In addition, after the treatment of a protein biosynthesis inhibitor, cycloheximide $(\mathrm{CHX})$, the half-life of HIF-1 $\alpha$ protein in TCEB2-overexpressing cells was much shorter than empty vector cells (Fig. 4C). These data indicates that TCEB2 promotes HIF-1 $\alpha$ protein degradation in OC cells. Along with the reduction of HIF- $1 \alpha$ protein in TCEB2-overexpressing cells, the transcriptional activity (HRE-luciferase) of HIF-1 $\alpha$ was also decreased (Fig. 4D).

$I L-8$ mediates the resistance of $O V$ cells to $B V$. In order to clarify the mechanisms of TCEB2-induced resistance to $\mathrm{BV}$, we investigated the expression of IL-8, which has been reported to mediate VEGF-A-independent angiogenesis in many cancer (17-19). Interestingly, IL-8 was significantly increased in TCEB2-overexpressing cells (Fig. 5A) and AR tumors exhibited significantly elevated IL-8 compared to $\mathrm{S}$ tumors (Fig. 5B). Although TCEB2-overexpressing cells and the HUVEC cells co-cultured with TCEB2-overexpressing cells were shown to be resistant to BV (Fig. 3A and B), both of them were sensitive to IL-8 neutralizing antibody (IL-8 Ab, Fig. 5C). Furthermore, we investigated the potential implication of a novel strategy which combined BV and IL- $8 \mathrm{Ab}$ in OC cells, and found that simultaneous treatment of BV and IL-8 Ab exhibited enhanced effect of growth inhibition on co-cultured HUVEC and SKOV3 cells (Fig. 5D and E). Collectively, these data indicate that TCEB2 promotes $\mathrm{OC}$ cells resistance to $\mathrm{BV}$ via upregulation of IL-8 (Fig. 5F).

\section{Discussion}

Clinically, BV has been approved as a single agent for glioblastoma (20), and also approved in combination with standard chemotherapy or immunotherapy for the treatment of metastatic colorectal cancer (21), non-small cell lung cancer (22), renal cell carcinoma (23) and advanced ovarian cancer $(24,25)$. In OC, the clinical efficacy of BV has been extensively evaluated in a number of trials. BV as single agent and in combination with chemotherapy has shown to improve PFS to a certain degree $(24,26)$, but results obtained from these trails seem to be mixed. Even though BV was administered at the same schedule, in the study of Burger et al (24), $21.0 \%$ clinical responses [including complete responses (CR) and partial responses (PR)] and 40.3\% improved FPS for at least 6 months were observed, however, the study of Cannistra et al (9) only demonstrated a $15.9 \%$ PR rate, also an $11 \%$ risk for gastrointestinal perforation, resulting in early termination of the experiment because of safety concerns. 
A

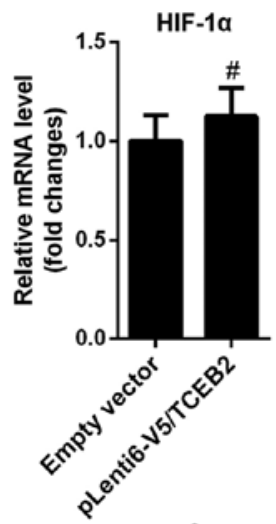

B

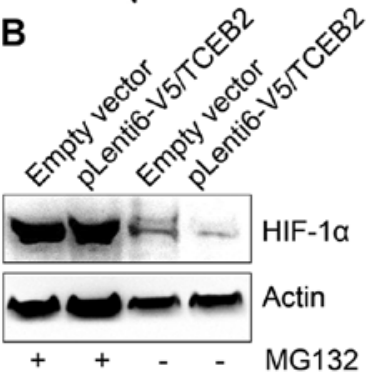

C
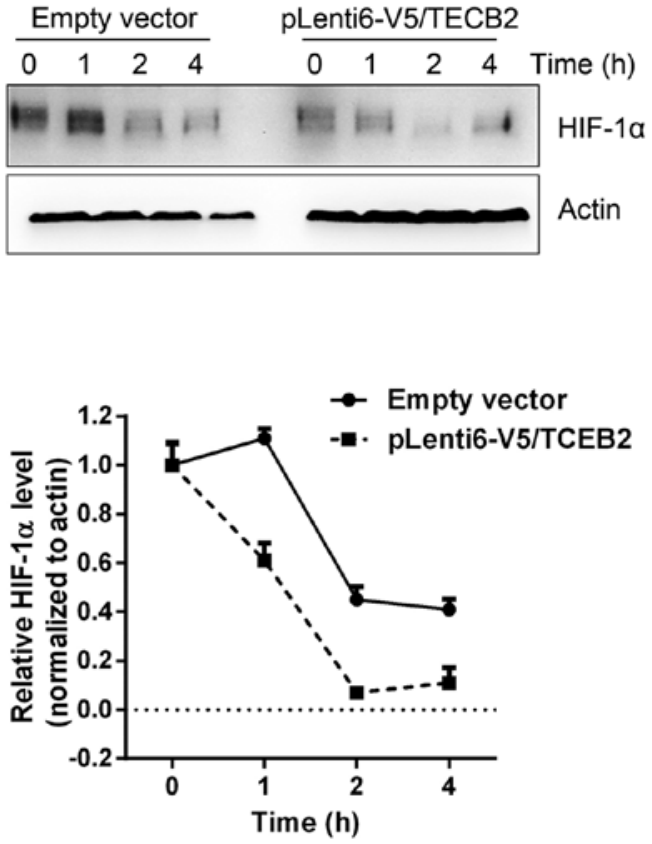

D

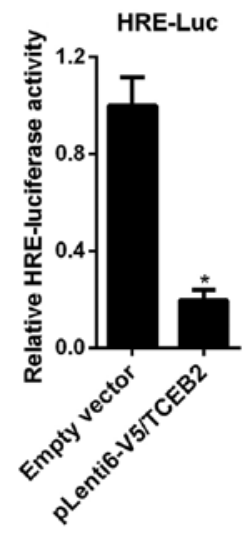

Figure 4. TCEB2 promotes HIF-1 $\alpha$ degradation. (A) Real-time PCR of HIF-1 $\alpha$ mRNA expression in empty vector or TCEB2- overexpressing SKOV3 cells. (B) Western blot analysis of HIF-1 $\alpha$ protein expression in empty vector or TCEB2-overexpressing SKOV3 cells with or without proteasome inhibitor MG132 treatment $(10 \mu \mathrm{M}, 9 \mathrm{~h})$. (C) Empty vector or TCEB2-overexpressing SKOV3 cells were pre-treated with protein biosynthesis inhibitor cycloheximide (CHX, $7.5 \mu \mathrm{g} / \mathrm{ml}$ ) for $4 \mathrm{~h}$, and HIF-1 $\alpha$ protein levels at the indicated time after CHX treatment were determined by western blot analysis. The lower pannel shows the quantification of HIF-1 $\alpha$ levels. (D) Hypoxia response element (HRE)-luciferase activity assay in empty vector or TCEB2-overexpressing SKOV3 cells. ${ }^{*} \mathrm{P}<0.05 ;{ }^{*} \mathrm{P}>0.05$.
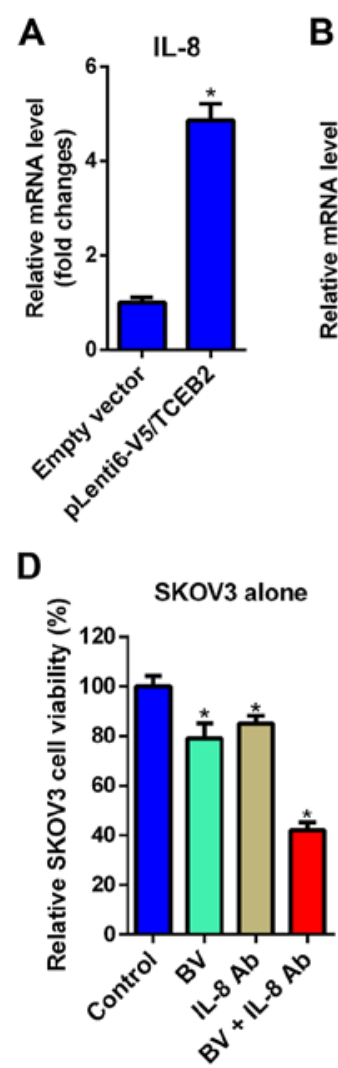

B

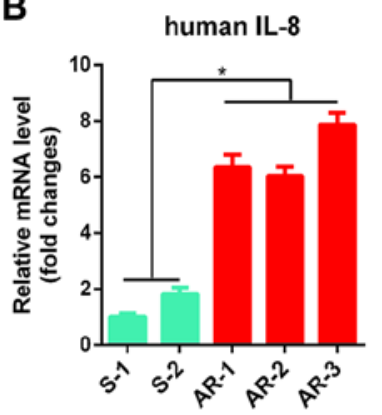

E

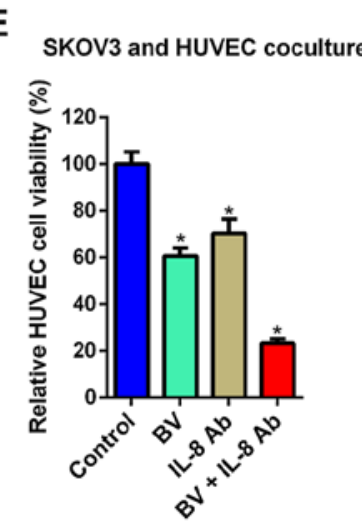

C
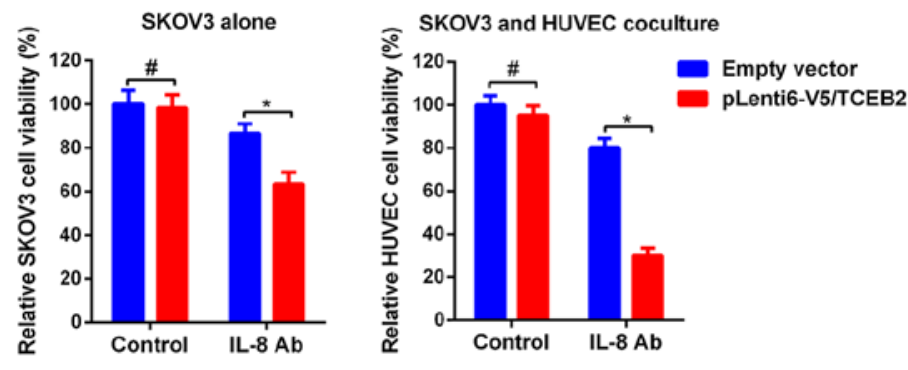

F

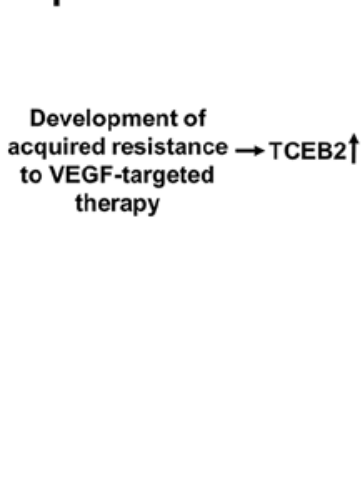

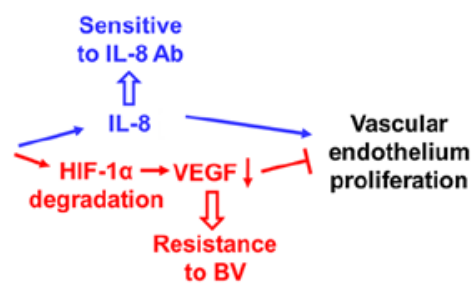

Sensitive
to IL-8 Ab

Figure 5. IL-8 mediates the TCEB2-regulated resistance to BV. (A) Real-time PCR of IL-8 expression in empty vector or TCEB2-overexpressing SKOV3 cells. (B) Real-time PCR detecting IL-8 expression in sensitive (S) and acquired resistant (AR) OC subcutaneous tumors. (C) Left, cell viability of empty vector or TCEB2-overexpressing SKOV3 cells treated with control or IL-8 Ab $(0.5 \mu \mathrm{g} / \mathrm{ml})$ for $48 \mathrm{~h}$. Right, cell viability of HUVEC cells co-cultured with empty vector or TCEB2-overexpressing SKOV3 cells under the treatment of control or IL-8 Ab for $48 \mathrm{~h}$. (D) Cell viability of SKOV3 cells treated with control, BV and IL-8 Ab alone or in combination. (E) Cell viability of HUVEC co-cultured with SKOV3 under the treatment of control, BV and IL-8 Ab alone or in combination. (F) Schematic diagram showing how TCEB2 promotes the development of acquired resistance to VEGF-targeted therapy. $\mathrm{P}<0.05$; ${ }^{*} \mathrm{P}>0.05$. 
Our results from animal models suggest a low response rate of OC cells to BV (2/6 sensitivity, 2/6 primary resistance and $3 / 6$ with initial response but rapidly developing resistance). Indeed, low response to BV have been shown in other solid tumors. For example, anti-angiogenic therapies are the firstline treatment for metastatic renal cell carcinoma, however, the response rate of patient to BV is only $31 \%$ (27). The low response rate, rapid development of resistance and high drug toxicity observed in some cases make it necessary to either understand the mechanisms of resistance, or to exploit better therapeutic strategies.

The underlying mechanisms of tumor cell resistance to anti-angiogenic agents are complicated. Firstly, VEGF/VEGFR-independent signaling, such as, HGF/c-Met, FGF/FGFR, Ang/Tie2 and immunocytokines (e.g., IL-8, IL-11) are also reported to play important roles in angiogenesis, thus may escape from the anti-VEGF and anti-VEGFR therapies $(17,28)$. Secondly, mutations in target genes during the treatment may lead to off-target therapeutics (29). Thirdly, insufficient drug concentration in the circulation and incomplete blockage of angiogenic signaling (29). Fourthly, tumor microenvironmental factors, such as inflammatory and stroma cells involved in angiogenesis are not affected by the currently used agents (15). Fifthly, tumor cell metabolism reprogramming may help to adapt to the treatment and survive in the poorly vascularized and low nutrition conditions (30). The present study suggests that when VEGF-A is suppressed during the treatment of BV, tumor cells will shift to a complementary manner (IL-8 mediated signaling) to maintain angiogenesis. Besides, decreased VEGF-A expression in OC administered BV was also observed in the study of Smerde et al (31).

TCEB2 can function as both a regulatory subunit in the transcription factor B (SIII) complex and an adapter protein in the proteasomal degradation of target proteins via different E3 ubiquitin ligase complexes, including the von Hippel-Lindau ubiquitination complex (VHL) $(12,13)$. VHL specifically targets HIF- $\alpha$ for degradation in normoxic condition (32). Our results demonstrate that TCEB2 promotes HIF-1 $\alpha$ degradation in OC cells, and expectedly, suppresses VEGF-A which is a known direct target gene of HIF-1 $\alpha$. TCEB2 also upregulates IL-8 which is a critical factor mediating cells resistant to anti-VEGF agents, however, how TCEB2 regulates IL-8 is not defined in the present study and needs to be further studied. In addition, the finding of TCEB2 associated with OC cells resistant to $\mathrm{BV}$ also indicates that TCEB2 may serve as a predictive biomarker of response for BV treatment, and thus may help in stratifying patients before treatment. Although the predictive implication of VEGF-A has not been studied in OC, amplification of VEGF-A gene has been reported to predict sensitivity to anti-angiogenic agent in hepatocellular carcinomas (33). Furthermore, based on the observation that IL-8 is upregulated in BV-resistant OC cells, this study also provides an alternative strategy of simultaneously targeting VEGF-A and IL-8 for OC.

\section{References}

1. Siegel R, Ma J, Zou Z and Jemal A: Cancer statistics, 2014. CA Cancer J Clin 64: 9-29, 2014.
2. Sonoda Y: Management of early ovarian cancer. Oncology (Williston Park) 18: 343-362, 2004.

3. Katsumata N, Yasuda M, Isonishi S, Takahashi F, Michimae H, Kimura E, Aoki D, Jobo T, Kodama S, Terauchi F, et al; Japanese Gynecologic Oncology Group: Long-term results of dose-dense paclitaxel and carboplatin versus conventional paclitaxel and carboplatin for treatment of advanced epithelial ovarian, fallopian tube, or primary peritoneal cancer (JGOG 3016): A randomised, controlled, open-label trial. Lancet Oncol 14: 1020-1026, 2013.

4. Vaughan S, Coward JI, Bast RC Jr, Berchuck A, Berek JS, Brenton JD, Coukos G, Crum CC, Drapkin R, Etemadmoghadam D, et al: Rethinking ovarian cancer: Recommendations for improving outcomes. Nat Rev Cancer 11: 719-725, 2011.

5. Coward JI, Middleton K and Murphy F: New perspectives on targeted therapy in ovarian cancer. Int $\mathbf{J}$ Womens Health 7: 189-203, 2015.

6. Teplinsky E and Muggia F: Targeting HER2 in ovarian and uterine cancers: Challenges and future directions. Gynecol Oncol 135: 364-370, 2014.

7. Bamberger ES and Perrett CW: Angiogenesis in epithelian ovarian cancer. Mol Pathol 55: 348-359, 2002.

8. Longo R, Sarmiento R, Fanelli M, Capaccetti B, Gattuso D and Gasparini G: Anti-angiogenic therapy: Rationale, challenges and clinical studies. Angiogenesis 5: 237-256, 2002.

9. Cannistra SA, Matulonis UA, Penson RT, Hambleton J, Dupont J, Mackey H, Douglas J, Burger RA, Armstrong D, Wenham R, et al: Phase II study of bevacizumab in patients with platinum-resistant ovarian cancer or peritoneal serous cancer. J Clin Oncol 25: 5180-5186, 2007.

10. Garcia AA, Hirte H, Fleming G, Yang D, Tsao-Wei DD, Roman L, Groshen S, Swenson S, Markland F, Gandara D, et al: Phase II clinical trial of bevacizumab and low-dose metronomic oral cyclophosphamide in recurrent ovarian cancer: A trial of the California, Chicago, and Princess Margaret Hospital phase II consortia. J Clin Oncol 26: 76-82, 2008

11. Spannuth WA, Sood AK and Coleman RL: Angiogenesis as a strategic target for ovarian cancer therapy. Nat Clin Pract Oncol 5: 194-204, 2008.

12. Garrett KP, Aso T, Bradsher JN, Foundling SI, Lane WS, Conaway RC and Conaway JW: Positive regulation of general transcription factor SIII by a tailed ubiquitin homolog. Proc Natl Acad Sci USA 92: 7172-7176, 1995.

13. Stebbins CE, Kaelin WG Jr and Pavletich NP: Structure of the VHL-ElonginC-ElonginB complex: Implications for VHL tumor suppressor function. Science 284: 455-461, 1999.

14. Zhou J, Wu K, Gao D, Zhu G, Wu D, Wang X, Chen Y, Du Y, Song W, Ma Z, et al: Reciprocal regulation of hypoxia-inducible factor $2 \alpha$ and GLI1 expression associated with the radioresistance of renal cell carcinoma. Int J Radiat Oncol Biol Phys 90: 942-951, 2014.

15. Cascone T, Herynk MH, Xu L, Du Z, Kadara H, Nilsson MB, Oborn CJ, Park YY, Erez B, Jacoby JJ, et al: Upregulated stromal EGFR and vascular remodeling in mouse xenograft models of angiogenesis inhibitor-resistant human lung adenocarcinoma. J Clin Invest 121: 1313-1328, 2011.

16. Ke Q and Costa M: Hypoxia-inducible factor-1 (HIF-1). Mol Pharmacol 70: 1469-1480, 2006.

17. Grepin R, Guyot M, Jacquin M, Durivault J, Chamorey E, Sudaka A, Serdjebi C, Lacarelle B, Scoazec JY, Negrier S, et al: Acceleration of clear cell renal cell carcinoma growth in mice following bevacizumab/Avastin treatment: The role of CXCL cytokines. Oncogene 31: 1683-1694, 2012.

18. Huang D, Ding Y, Zhou M, Rini BI, Petillo D, Qian CN, Kahnoski R, Futreal PA, Furge KA and Teh BT: Interleukin-8 mediates resistance to antiangiogenic agent sunitinib in renal cell carcinoma. Cancer Res 70: 1063-1071, 2010.

19. Abraham RT: Chemokine to the rescue: Interleukin- 8 mediates resistance to PI3K-pathway-targeted therapy in breast cancer. Cancer Cell 22: 703-705, 2012.

20. Kreisl TN, Kim L, Moore K, Duic P, Royce C, Stroud I, Garren N, Mackey M, Butman JA, Camphausen K, et al: Phase II trial of single-agent bevacizumab followed by bevacizumab plus irinotecan at tumor progression in recurrent glioblastoma. J Clin Oncol 27: 740-745, 2009.

21. Hurwitz H, Fehrenbacher L, Novotny W, Cartwright T, Hainsworth J, Heim W, Berlin J, Baron A, Griffing S, Holmgren E, et al: Bevacizumab plus irinotecan, fluorouracil, and leucovorin for metastatic colorectal cancer. N Engl J Med 350: 2335-2342, 2004. 
22. Sandler A, Gray R, Perry MC, Brahmer J, Schiller JH, Dowlati A, Lilenbaum R and Johnson DH: Paclitaxel-carboplatin alone or with bevacizumab for non-small-cell lung cancer. N Engl J Med 355: 2542-2550, 2006

23. Escudier B, Bellmunt J, Négrier S, Bajetta E, Melichar B, Bracarda S, Ravaud A, Golding S, Jethwa S and Sneller V: Phase III trial of bevacizumab plus interferon alfa-2a in patients with metastatic renal cell carcinoma (AVOREN): Final analysis of overall survival. J Clin Oncol 28: 2144-2150, 2010.

24. Burger RA, Brady MF, Bookman MA, Fleming GF, Monk BJ, Huang H, Mannel RS, Homesley HD, Fowler J, Greer BE, et al; Gynecologic Oncology Group: Incorporation of bevacizumab in the primary treatment of ovarian cancer. N Engl J Med 365 2473-2483, 2011.

25. PerrenTJ,SwartAM,PfistererJ,Ledermann JA,Pujade-LauraineE, Kristensen G, Carey MS, Beale P, Cervantes A, Kurzeder C, et al; ICON7 Investigators: A phase 3 trial of bevacizumab in ovarian cancer. N Engl J Med 365: 2484-2496, 2011.

26. Pujade-Lauraine E, Hilpert F, Weber B, Reuss A, Poveda A Kristensen G, Sorio R, Vergote I, Witteveen P, Bamias A, et al Bevacizumab combined with chemotherapy for platinum-resistant recurrent ovarian cancer: The AURELIA open-label randomized phase III trial. J Clin Oncol 32: 1302-1308, 2014

27. Escudier B, Pluzanska A, Koralewski P, Ravaud A, Bracarda S, Szczylik C, Chevreau C, Filipek M, Melichar B, Bajetta E, et al; AVOREN Trial investigators: Bevacizumab plus interferon alfa-2a for treatment of metastatic renal cell carcinoma: A randomised, double-blind phase III trial. Lancet 370: 2103-2111, 2007.
28. Shojaei F, Lee JH, Simmons BH, Wong A, Esparza CO, Plumlee PA, Feng J, StewartAE, Hu-Lowe DD and Christensen JG: $\mathrm{HGF} / \mathrm{c}-\mathrm{Met}$ acts as an alternative angiogenic pathway in sunitinibresistant tumors. Cancer Res 70: 10090-10100, 2010.

29. Figlin RA, Kaufmann I and Brechbiel J: Targeting PI3K and mTORC2 in metastatic renal cell carcinoma: New strategies for overcoming resistance to VEGFR and mTORC1 inhibitors. Int J Cancer 133: 788-796, 2013

30. Metallo CM, Gameiro PA, Bell EL, Mattaini KR, Yang J, Hiller K, Jewell CM, Johnson ZR, Irvine DJ, Guarente L, et al: Reductive glutamine metabolism by IDH1 mediates lipogenesis under hypoxia. Nature 481: 380-384, 2012.

31. Smerdel MP, Steffensen KD, Waldstrøm M, Brandslund I and Jakobsen A: The predictive value of serum VEGF in multiresistant ovarian cancer patients treated with bevacizumab. Gynecol Oncol 118: 167-171, 2010.

32. Haase VH: The VHL tumor suppressor: Master regulator of HIF Curr Pharm Des 15: 3895-3903, 2009.

33. Horwitz E, Stein I, Andreozzi M, Nemeth J, Shoham A, Pappo O, Schweitzer N, Tornillo L, Kanarek N, Quagliata L, et al: Human and mouse VEGFA-amplified hepatocellular carcinomas are highly sensitive to sorafenib treatment. Cancer Discov 4: 730-743, 2014. 